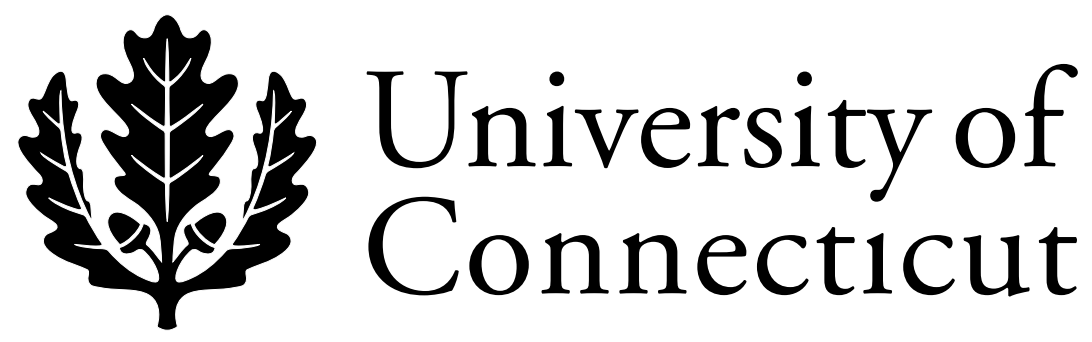

Department of Economics Working Paper Series

\title{
Optimal Central Banker Contracts and Common Agency
}

Georgios E. Chortareas

Bank of England

Stephen M. Miller

University of Connecticut

Working Paper 2000-03

2000, revised June 2002

341 Mansfield Road, Unit 1063

Storrs, CT 06269-1063

Phone: (860) 486-3022

Fax: (860) 486-4463

http://www.econ.uconn.edu/ 


\begin{abstract}
This paper considers the contacting approach to central banking in the context of a simple common agency model. The recent literature on optimal contracts suggests that the political principal of the central bank can design the appropriate incentive schemes that remedy for time-inconsistency problems in monetary policy. The effectiveness of such contracts, however, requires a central banker that attaches a positive weight to the incentive scheme. As a result, delegating monetary policy under such circumstances gives rise to the possibility that the central banker may respond to incentive schemes offered by other potential principals. We introduce common agency considerations in the design of optimal central banker contracts. We introduce two principals - society (government) and an interest group, whose objectives conflict with society's and we examine under what circumstances the government-offered or the interest-group-offered contract dominates. Our results largely depend on the type of bias that the interest group contract incorporates. In particular, when the interest group contract incorporates an inflationary bias the outcome depends on the principals' relative concern of the incentive schemes' costs. When the interest group contract incorporates an expansionary bias, however, it always dominates the government contract. A corollary of our results is that central banker contracts aiming to remove the expansionary bias of policymakers should be written explicitly in terms of the perceived bias.
\end{abstract}

Journal of Economic Literature Classification: E42, E52, E58

Keywords: central banker contracts, common agency, inflation bias 


\section{Introduction}

Two basic remedies for the time-inconsistency of monetary policy exist, reputation and institutional design. More recent analyses emphasize institutional design, rather than reputation. That literature encompasses the following strands. The "conservative central banker" approach (e.g., Rogoff 1985) recommends the appointment of a central banker who is more inflation averse than society. The “targeting” approach (e.g., Svensson 1997, Garfinkel and Oh 1993, Canzoneri et al. 1997) requires that the central banker adopt explicit targets. ${ }^{1}$ The "legislative" approach (e.g., Persson and Tabellini 1993) argues for central banker independence and a clear price stability mandate. The "contracting" approach (e.g., Walsh 1995a,b, Persson and Tabellini 1993, Waller 1995, Frattianni et al. 1997) develops an optimal incentive scheme that delivers monetary policy outcomes equivalent to the first best. $^{2}$

The contracting approach to central banking, which is the most recent, has received less attention. Recent theoretical work using the principal-agent framework shows that efficient punishment and transfers mechanisms exist, ensuring monetary policy outcomes equivalent to those under credible commitment. Walsh (1995a) and Persson and Tabelinni (1993) develop formal agent-theoretic models for central bank decision-making. Informal discussions of government (society) and central bank interaction in a principal-agent scheme also appear in Brunner (1985) and Mayer (1990). Contracts not only deliver the optimal policy outcomes, but also are not subject to the unwanted trade-off between credibility and flexibility, which is typical of other institutional solutions. In addition, they provide a highly transparent form of monetary policy delegation. ${ }^{3}$ The most important virtue of the principal-agent approach, however,

\footnotetext{
${ }^{1}$ The most widely discussed target is inflation. Inflation targeting does not preclude the use of intermediate monetary targets, provided that priority remains with the inflation target (Leiderman and Svensson, 1995). Canzoneri et al. (1997) compare inflation and exchange rate targeting.

${ }^{2}$ Those institutional approaches, however, are not mutually exclusive. For example, a "contract" requires some explicit inflation or monetary aggregate target. New Zealand's Reserve Bank Act of 1989, which most frequently is interpreted as a central banker contract (e.g., Walsh 1995b), mandates that the central bank and the government agree on and publicly announce the "Policy Target Agreements" (Fischer 1995). The benefits of appointing a conservative central banker require a high degree of central bank independence, and so on.

${ }^{3}$ Chortareas et. al. (2002) find that a higher degree of central bank transparency is associated with lower average inflation.
} 
relates not to the detailed mapping of actual policy arrangements but rather to the fact that it provides a theoretically consistent framework for understanding monetary policy delegation. The principal-agent framework allows the consideration of delegation issues, often neglected monetary policy discussions. Policy delegation issues constitute an important topic within the literature on policymaking. Common agency represents one important such aspect.

The literature on central banker contracts to date only considers delegated bilateral agency (i.e., one principal and one agent). Moreover, the agent-theoretic models almost exclusively consider the supply side of monetary policy (i.e., the institutional design and policy outcomes as explained by incentive schemes), ${ }^{4}$ giving the demand side for policy outcomes and relevant institutions scant attention. Existing models implicitly assume that the government rules the demand side. The effectiveness of central banker contracts requires that a positive weight attach to the incentive scheme. As a result, delegating monetary policy under such circumstances gives rise to the possibility that the central banker may respond to incentive schemes offered by other potential principals. This paper considers an extended principal-agent framework that allows for more than one principal with differing preferences. Our findings cast doubt on the efficacy and desirability of such incentive contracts under common agency. In particular, we show that when monetary policy is delegated through inflation contracts and a second potential principal offers a competing output or inflation contract, the government contract the government contract does not always deliver the commitment-equivalent results. An output contract offered by the interest group neutralizes the government-inflation-contract effect on inflationary expectations and inflation. When both principals offer inflation contracts, results depend critically on their relative concern about the contract costs. A corollary of our analysis is that central banker contracts aimed to remove the expansionary bias of policymakers should be written explicitly in terms of the perceived bias.

\footnotetext{
${ }^{4}$ Laffont and Tirole (1993) and Gordon (1975) discuss the "demand" and "supply" sides of regulation and inflation, respectively.
} 
The next section discusses the rationale for a common agency model in central banking, the characteristics of potential conflicting incentive schemes, and some possible real world applications. Section 3 provides the basic contracting model (and results) as applied to central banking. Section 4 develops a common-agency central-banking model under alternative assumptions about the potential principals' objectives and identifies the conditions under which an optimal contract exists. Section 5 discusses our results and compares them to the existing literature. Finally, section 6 concludes.

\section{Background and Rationale}

Within the bilateral agency literature on central bank contracts, the single principal is the government or society, who can write explicit (formal) contracts with the central banker. Models that permit heterogeneous preferences in society typically assume, at least implicitly, that social groups and organized interests with differing agendas advance them through the electoral channel. Competition between political parties for (re)election responds to those heterogeneous preferences. If the group of potential principals designs and offers a collective incentive scheme, then the existing models of central banker contracts apply. That observation includes those models that incorporate political competition as well. Political parties may have conflicting objectives, but if institutional procedures generate a collective decision regarding the central banker's contract, the single principal approach still holds (especially after bargaining occurs).

What if co-operation among potential principals does not occur? What if a multiplicity of principals with conflicting goals do not internalize their conflicts through the political (electoral) process? The effort to influence monetary (economic) policy follows multiple channels and emerges not only through the electoral process and pressure from other arms of government (e.g., the parliament), but also through additional political activity such as lobbying, press criticism, and so on.

This paper considers the potential role of interest groups in an extended principal-agent framework that includes a multiplicity of potential principals. The central banker can enter into a formal contract with the government as well as an informal contract with a private interest group. The 
government contract emerges from the political process as the collective decision of society; the interest group contract reflects a significant disaffected minority. Our model corresponds partly to an intrinsic common agency problem, which according to Bernheim and Whinston (1986a) refers to the situation “when an individual is 'naturally' endowed with the right to make a particular decision affecting other parties, who may in turn attempt to influence that decision" (p. 924). ${ }^{5}$ In contrast to Bernheim and Whinston (1986a), however, who restrict attention to principals with a constitutionally guaranteed power to offer incentive contracts, we consider the possibility of informal contracts, as in Grossman and Helpman (1994a,b, 1995). Our model incorporates elements of both delegated and intrinsic agency, the former referring to the society-government relationship, and the latter to both the government-central banker and interest group-central banker relationships.

Our central banker is a self-interested utility maximizer, whose decision depends on private rewards. Laffont and Tirole (1993) discuss in detail the explicit form that such transfers can take. Dixit (1996b) suggests that the incentives (penalties or rewards) in policymaking whether financial or nonmonetary should be interpreted broadly to include career concerns and status (power). Brunner (1985) argues that central bankers carefully evaluate their actions because they affect their "political status and future market opportunities in the private and public sector" (p. 15). Blinder (1998) also indicates that the promised rewards by the private sector to a central banker (i.e., our implicit interest group-central banker contract) can overshadow his pecuniary incentives as a public official. We abstract from discussing the explicit form of the central banker's reward scheme, since we focus on the theoretical efficacy of central banker contracts.

\footnotetext{
${ }^{5}$ The same authors define delegated common agency as the situation where "several parties voluntarily (and perhaps independently) bestow their right to make certain decisions upon a single (common) agent" (p.923).
} 
A contract between an interest group and the central banker must be informal, and typically not explicitly announced. ${ }^{6}$ Laffont and Tirole (1993) label such contracts as quasi-enforceable, meaning that the parties' willingly enforce their own promises rather than turning to the courts. ${ }^{7}$

Our model provides insights to several real world situations. First, different sectors or industries may have different preferences between inflation and output. Posen $(1993,1995)$ suggests that the relationship between the institutional characteristics of central banks, in particular their degree of independence, and their inflation performance reflects the financial sector's aversion to inflation ("financial opposition to inflation"). Posen (1993) observes that "the changing relative strength of interests in society, not the institution's structure, is the source of policy decisions" (p. 46, emphasis added). The interests of the banking and industrial sectors may not always conflict, but they are not always consistent. Of course, the structure of the financial system affects the shaping of these interests. For example, corporate and bank linkages are much stronger in Japan, Germany, and France as compared to the US and the UK, where firms rely more heavily on capital markets for financing. ${ }^{8}$

Second, the design and implementation of monetary policy by supranational institutions, such as the European Central Bank (ECB), increases the potential for multiple principals. Dewatripont et al. (1995) note that "it is difficult to identify a principal on whose behalf the ECB can act, leaving it exposed to accusations that it is a body accountable to no one" (pg. 140). Eichengreen (1996) discusses some relationships between interest groups and the ECB. Those interest groups represent the desires of national governments from high-debt EMU member countries that may lobby for low interest rates. According to Eichengreen (1996) "some observers worry that the ECB board members will be unduly responsive to

\footnotetext{
${ }^{6}$ Grossman and Helpman (1995, p.678) make the same assertion.

${ }^{7}$ Blinder (1998) criticizes the principal-agent contacts in central banking, arguing that changes in central banker salaries probably cannot affect their motives seriously. Blinder, however, imagines government contracts. Private sector contracts, as in this paper, may negate Blinder's point. As Dixit (1996a) argues "the marginal rewards for producing an outcome of greater value to society, or the marginal penalties for doing worse, are generally a very low percentage of the value added or lost" (p.94).

${ }^{8}$ For a more detailed discussion of how the differences in bank-industry relations shape the private sector's preferences, see Henning (1994).
} 
special interest groups" (p. 18). Eichengreen (1996) also argues that lobbing efforts in Europe will emerge to the extent that the confidence in the ECB's efficacy and independence is shaken, further eroding its autonomy. Increased lobbying activity results in multiple equilibria. As we show below, the contract itself generates ambiguity regarding the central banker's preferences and induces lobbying activity. Nonsynchronized business cycles within the European Union can also constitute a reason for different preferences of national policymakers over the ECB's policy. In a model where the ECB is the common agent of citizens of different countries, each country represents a potential principal. More realistically, alliances will emerge for various issues. For example, it is realistic to expect conflicting groups on inflation, those who are happy with the ECB's policy and those who are not. Each national government is an interest group. The "payment" to the central banker can be the promise of later employment in the top hierarchy of the national government. Finally, Dixit and Jensen (2000) model the relationship between the members of a common currency area and the common central bank as a multi-principal relationship where monetary policy is delegated through Walsh-type contracts. They show that ex-ante politicization can be Pareto optimal because the resulting Nash equilibrium produces a weighted average of the countries' most preferred policy. These findings, however, critically depend on the assumptions that each member country commits to the particular contract (i.e., there exist only ex ante politicization and not ex post politicization), that the principals' objectives are congruent, and that the central banker cares only about the incentive scheme (and not the social loss). When the central banker cares about both the countries' welfare and the incentive schemes, an inefficiently low inflation rate emerges.

Third, Ahmed and Miller (1998) show in a two sector (classical/Keynesian) model with traded and nontraded goods that the effects of monetary and exchange rate policy in each sector depend on the degree of unionization and openness. Monetary policy can have asymmetric effects and different welfare effects on those sectors. Interest groups that represent the various sectors can lobby to achieve favorable monetary and exchange rate policies. Waller (1992) also considers multisector economies where the different sectors have different preferences on the central banker's inflation conservativeness. The 
disagreement over the degree of central banker's conservatism disappears under a central banker contract, since central banker contracts do not imply a lower inflation-higher output variability trade off.

Finally, other multiple-principal cases emerge with the possibility of divided government, where different branches of government (e.g., US and France) possess different macroeconomic preferences. ${ }^{9}$

\section{Basic Model}

This section develops the typical model of monetary policy when policymakers (central bankers) have time-inconsistent preferences, which mirrors the Barro-Gordon model of monetary policy (e.g., Walsh, 1995a, Waller, 1995, Jensen 1997, Canzoneri 1985). The economy experiences nominal wage contracts and a Lucas supply function, so that inflation surprises can increase output beyond the natural rate:

$$
y=y^{n}+\alpha\left(\pi-\pi^{e}\right)+\varepsilon,
$$

where $y=$ the actual output, $y^{n}=$ the natural rate of output, $\pi=$ the inflation rate, $\pi^{e}=E_{t}\left(\pi_{t+1} \mid I_{t}\right)=$ the expected inflation conditional on information available at time t, and $\varepsilon$ is an identically and independently distributed aggregate supply (productivity) shock with $E(\varepsilon)=0$ and no persistence. The supply shock permits a potential stabilizing role for monetary policy, if the monetary authority has superior information about its occurrence. For simplicity, we drop all time subscripts.

We assume that the ex-ante one-period social loss function is given by

$$
\Lambda^{S}=\Lambda^{C B}=\left(y-y^{*}\right)^{2}+\beta \pi^{2}
$$

where $y^{*}$ denotes targeted output. Society has the same loss function as the central banker and therefore the same expansionary bias $z\left(y^{*}=y^{n}+z\right.$ with $\left.z \geq 0\right) .{ }^{10}$ Superscripts $\mathrm{S}$ and $\mathrm{CB}$ denote society and the central bank, respectively. The term $\beta(\beta \in[0, \infty])$ reflects society's aversion to inflation as well as the

\footnotetext{
${ }^{9}$ For a discussion of how divided government and institutional balancing can affect macroeconomic policy decisions, see Alesina and Rosenthal (1995).

${ }^{10}$ Typically, principal-agent models of monetary policy assume that the political principal (government) and the central banker share the same utility function (e.g., Walsh 1995a, Persson and Tabellini 1993). Exceptions are Waller's (1995) "rogue" central banker and Fratianni et al.’s (1997) politically elected central banker.
} 
central banker's conservatism (inflation aversion). A higher $\beta$ implies a higher weight attached to inflation stabilization as compared to output stabilization. The desired inflation rate is zero for simplicity $\left(\pi^{*}=0\right)$.

The inflation rate depends on the monetary aggregate growth rate $(m)$, which is directly controlled by the central banker as follows:

$$
\pi=m+v-\gamma \varepsilon,
$$

where $v$ is a stochastic control error or velocity shock, with $E(v)=0, E\left(v^{2}\right)=\sigma_{v}^{2}$, and $E(v \varepsilon)=0$. The velocity shock is observed only after expectations have been formed and monetary policy has been set. The term $(-\gamma)$ shows the countercyclical response of the central banker to unexpected supply shocks. The central banker's choice variables, therefore, are $\mathrm{m}$ and $\gamma$. We focus on $\mathrm{m}$, taking $\gamma$ as given.

Walsh (1995a) introduces a linear incentive scheme in the central banker's loss function that penalizes deviations of actual inflation from its target. ${ }^{11}$ This incentive scheme takes the form $\left(t_{0}-t \pi\right)$, where $t_{0}$ is a fixed reward and $t$ a marginal penalty rate. Thus, the inflation-contract-augmented central banker's loss function is as follows:

$$
\Lambda^{C B}=\left(y-y^{*}\right)^{2}+\beta \pi^{2}-\left(t_{0}-t \pi\right)
$$

By comparing the central banker's reaction function in the presence of the incentive scheme and under commitment, one can show that an optimal penalty rate $\left(t^{*}\right)$ exists that produces policy outcomes equivalent to those under credible commitment. This penalty rate $\left(t^{*}=2 \alpha z\right)$ counteracts the central banker's inflationary bias by working as a Pigovian corrective tax, and raises the marginal costs of higher money growth rates for the central banker. Deriving the reaction function of the central banker and the corresponding money growth and inflation expectations (reaction function) of the public sector produces in the presence of the optimal contract expectations of money growth and inflation that are zero.

\footnotetext{
11 Thus, the central banker cares about he incentive scheme; otherwise, the contracting approach does not make sense.
} 


\section{Equilibrium with Two Principals with Conflicting Objectives}

\section{Definition of Equilibrium}

We now construct the problem of two principals -- government (society) and the disaffected interest group -- with conflicting objectives. The sequence of events is as follows. At the beginning of the period, the government offers a contract that makes the central banker's payment contingent on inflation performance. Simultaneously, the interest group offers a competing incentive scheme that makes the central bankers reward contingent on either inflation or output performance. The private sector forms expectations and the central banker sets the policy instrument after observing a stochastic supply-side shock. Then, inflation and output outcomes are realized and the central banker is rewarded. We assume that both principals observe the same policy outcomes, and that neither has private information about an operating or intermediate monetary policy target.

Thus, the interest group contract can thwart the interests of the government (society). The uncertainty and its adverse implications for the inflation rate disappear, if the government can design a dominant contract. Such contracts, if they exist, incorporate both the central banker's and the interest group's optimization problems. If the government offers a credible, dominant contract, then the private sector sets its expectations about the money growth rate to zero. We first define the game's equilibrium, and then we characterize the equilibrium. Finally, we derive the conditions necessary, if any, for a dominant contract.

The private sector (public) knows that the interest group can offer a contract to the central banker. Unless the public observes that the government offers a dominant contract, it does not set its inflation expectation to zero and the policy outcomes are not equivalent to that under commitment. We could also assume that the interest group offers a contract before the public forms expectations, and that the public knows the contract offer, but not its details. Or we could assume that the interest group extends the contract offer after the public sets its expectations, but that the public knows that an interest group contract will be offered. Our model can accommodate both assumptions. 
Another issue involves our assumption that the two contract offers occur simultaneously. In abstract models, the two principals solve their optimization problem and offer the contract to the agent simultaneously (Bernheim and Whinston 1986a, Dixit et al. 1997, Persson 1998). In more applied models, the government contract is specified first, and then the interest group makes a counter-offer (Spiller, 1990). That approach is more consistent with Bernheim and Whinston's (1986a) reformulation that decomposes the principal's offer in two steps: one that undoes the offer of the other principal and one that represents the net offer. All those researchers, however, solve the problems of the two principals simultaneously. Moreover, timing issues become irrelevant in the typical full-information model.

Our problem corresponds to a one-period, two-stage non-cooperative game with full information and three participants -- the central banker, the government (society), and a disaffected interest group. In the first stage, the two principals non-cooperatively determine the incentive schemes offered to the central banker. We assume global truthfulness. ${ }^{12}$ In the second stage, the central banker responds and chooses the rate of money growth. To narrow the possible equilibrium outcomes, the equilibrium Nash strategies must fulfil the subgame perfection condition, which requires that the player's strategies constitute a Nash equilibrium in each subgame. Our definition of equilibrium borrows from Bernheim and Whinston (1986a,b), Dixit et al. (1997), and Grossman and Helpman (1995).

The government offers the incentive scheme $t r=\left(t_{0}-t \pi\right)$ as in Walsh (1995a). The interest group offers either $\tau \rho=\left[\tau_{0}-\tau\left(y^{g}-y\right)\right]$ or $\tau \rho=\left[\tau_{0}-\tau(\hat{\pi}-\pi)\right]$, when the interest group has an output or inflation objective, respectively (where $y^{g}$ and $\hat{\pi}$ denote preferred values of output and inflation).

Definition: An equilibrium of our common agency problem consists of feasible incentive schemes [tr*, $\left.\tau \rho^{*}\right]$ and a policy outcome $\left[\mathrm{m}^{*}\right]$, such that [tr*] is the best response of the government to the contract offered by the interest group and $\left[\tau \rho^{*}\right]$ is the best response of the interest group to the contract offered by the government. Each incentive scheme [tr*, $\left.\tau \rho^{*}\right]$ is positive, continuous, and differentiable.

\footnotetext{
${ }^{12}$ Berheim and Whinston (1986b) discuss the truthful Nash equilibria as a refinement of the Nash set in the common agency model.
} 


\section{Central Bank Contracts and An Interest Group with an Output Objective}

Assume that a partisan interest (interest group) considers the natural output as socially unacceptable and lobbies the central bank. ${ }^{13}$ That interest group desires output $y^{g}\left(y^{g}=y^{n}+g\right.$, where $g>0$ is the expansionary bias of the interest group). The interest group offers a linear contract to the central banker that penalizes output performance below $y^{g}$ and rewards output performance above $y^{g}$. Thus, the interest group contract takes the form $\tau \rho=\tau_{0}-\tau\left(y^{n}+g-y\right) .{ }^{14}$ We also impose the restriction that $\tau_{0}-\tau\left(y^{n}+g-y\right)>0$ for $y>y^{n}$ and $\tau_{0}-\tau\left(y^{n}+g-y\right)=0$ for $y=y^{n}$. In other words, rewards from the interest group to the central banker are realized only when output exceeds its natural rate.

When both the government and the interest group offer contracts to the central banker, the central banker's loss function takes the explicit form:

$$
\Lambda^{C B}=\left[\left(y-y^{*}\right)^{2}+\beta \pi^{2}\right]-\xi\left[\tau_{0}-\tau\left(y^{n}+g-y\right)+\left(t_{0}-t \pi\right)\right] .
$$

The central banker dislikes deviations from the targeted output $\left(y^{*}\right)$ and inflation rate $\left(\pi^{*}=0\right)$. The contract with the government penalizes realized inflation rates higher than zero while the contract with the interest group penalizes realized output lower than $\left(y^{n}+g\right)$.

The relative preferences that the central banker attaches to the incentive schemes and to aggregate social welfare are reflected in $\xi$. Such loss (utility) functions appear in models where policymakers explicitly care about monetary rewards, such as the trade models by Dixit (1996a), Grossman and Helpman (1994a, 1995), and Levy (1999), where the rewards represent contributions to politicians. We also retain the assumption that the central banker has the expansionary bias $z$ and therefore the targeted

13 For example, the governing council members of the ECB may succumb to pressures by their national governments that desire more expansionary policy and promise future governmental positions in return. One difficulty arises, however. Since the public forms expectations rationally, output cannot exceed the natural rate and the central banker's reward by the interest group (which is contingent on output performance) is never realised. In other words, the interest group suffers from the same truncated rationality problem as the policymakers in the standard time-inconsistency models. The McCallum $(1995,1997)$ criticism arises at this point.

${ }^{14}$ An alternative model assumes that the interest group's preferences are linear in output as in Barro and Gordon (1983) with more output preferred to less. The results are similar provided that we impose the appropriate restrictions on the interest group's reward schedule. 
output is $y^{*}=y^{n}+z, z>0$. Finally, we normalize the reservation utility of the central banker to zero and assume that the participation constraint is satisfied

We consider a one-period model. The government writes a contract at the beginning of the period and offers the relevant reward to the central banker at the end of the period. The interest group communicates its desired policy to the central banker and offers the reward (conditional on central banker's actions) at the end of the period. We also assume that a central banker cannot serve more than one term.

Deriving the first-order conditions from minimizing equation (4) subject to the constraint of the economy and solving for $m$ gives the following central bank reaction function

$$
m=\left(\gamma-\frac{\alpha}{\left(\alpha^{2}+\beta\right)}\right) \varepsilon+\left(\frac{\alpha^{2}}{\alpha^{2}+\beta}\right) m^{e}+\left(\frac{\alpha^{2}}{\alpha^{2}+\beta}\right) z+\left(\frac{\xi}{2\left(\alpha^{2}+\beta\right)}\right)(\tau \alpha-t) .
$$

Thus, the public's expectations for the rate of money growth and inflation are given by

$$
E(m)=m^{e}=E(\pi)=\pi^{e}=\left(\frac{\alpha}{\beta}\right) z+\left(\frac{\xi}{2 \beta}\right)(\tau \alpha-t)
$$

The interest group's problem consists of minimizing the following loss function:

$$
\operatorname{Min}_{\tau} L^{I G}=\left[\left(y-y^{g}\right)^{2}+b \pi^{2}\right]+\psi\left[\tau_{0}-\tau\left(y^{g}-y\right)\right] .
$$

That is, the interest group penalizes the central banker for output below the desired level $\left(y^{g}\right)$. The weight $\psi$ captures the interest group's relative concern about the contract costs and its social loss. The weight $b$ captures the interest group's concern about inflation. We assume that the interest group, despite its preference for high output, is not indifferent to the inflation rate. It does place, however, less weight on inflation than government, so that $b<\beta$. The interest group knows that the central banker incorporates the offers of all potential principals when setting the policy instrument $(m)$, and also knows that the government makes its best offer $\left(t^{*}=t^{N}\right)$. The interest group cannot observe $v$ and $\varepsilon$. Thus, it sets $\pi=\pi^{e}=m^{e}$. Minimizing equation (7) subject to the central banker's reaction function (equation 5), and 
the public's expectations about inflation $\left(\pi^{e}=m^{e}\right)$, and taking the optimal government's penalty rate as given generates:

$$
\tau^{N}=\left(\frac{1}{\alpha}\right) t+\frac{2 \beta}{\xi \alpha}\left[\left(\frac{\psi \beta}{b \xi \alpha}\right) g-\left(\frac{\alpha}{\beta}\right) z\right]
$$

That is, the optimal penalty rate $\left(\tau^{N}\right)$ in the interest group's contract is a function of the central banker's own inflationary bias, the interest group's expansionary bias, and the penalty rate in the competing (government) incentive scheme.

Next, we solve the government's (society's) problem. The government's loss function depends on output, the inflation rate, and the costs of the optimal central banker contract as follows:

$$
\underset{t}{\operatorname{Min}} L^{G}=\left(y-y^{*}\right)^{2}+\beta \pi^{2}+\phi\left(t_{0}-t \pi\right)
$$

We assume that the government possesses the same degree of inflation aversion as the central banker.

Our model modifies the original Walsh (1995a) model by explicitly having the government concerned about the costs of the optimal contract. The existing literature implicitly assumes that the government does not care about contract costs. That assumption contradicts the basic elements of agency theory (principal-agent models). Furthermore, the social burden of the government transfer to the central banker exceeds the size of the transfer itself when the contract costs are financed through distortionary taxes. Finally, excessive transfers to central bankers may be politically unacceptable (see Chortareas and Miller, 2002).

The government minimizes the loss function given by equation (9) subject to the reaction functions of the central banker (equation 5) and the public, and taking the optimal interest group offer as given. Using $\pi=\pi^{e}=m^{e}$ and recalling that the government does not observe $v$ and $\varepsilon$, the resulting optimal penalty rate in the government's contract is as follows:

$$
t^{N}=\Omega\left(\frac{2 \beta}{\xi}\left(\frac{\alpha}{\beta}\right) z+\alpha \tau\right),
$$


where $\Omega=\left(\frac{\xi+\phi}{\xi+2 \phi}\right), 1 / 2 \leq \Omega \leq 1 .{ }^{15}$ Thus, the optimal penalty rate in the government's contract increases in the central banker's own inflation bias and in the optimal penalty rate in the interest group's contract, which itself depends on the interest group's expansionary bias. Note that while the first component of the required penalty rate becomes lower with a more "selfish" central banker, the last component does not depend on the central banker's "selfishness".

We solve for the optimal penalty rates in the government's and in the interest group's contracts. In other words, we want to express the Nash penalty rates in terms of the exogenously given inflationary and expansionary biases of the government, the interest group, and the central banker, [i.e., $t^{N}=t(g, z)$ and $\left.\tau^{N}=\tau(g, z)\right]$. The resulting optimal penalty rates in equilibrium are:

$$
\begin{aligned}
\tau^{N} & =\left(\frac{1}{1-\Omega}\right)\left(\frac{2 \beta}{\xi \alpha}\right)\left[\left(\frac{\psi \beta}{b \xi \alpha}\right) g-(1-\Omega)\left(\frac{\alpha}{\beta}\right) z\right], \text { and } \\
t^{N} & =\left(\frac{\Omega}{1-\Omega}\right)\left(\frac{2 \beta}{\alpha}\right)\left(\frac{\psi \beta}{b \xi^{2}}\right) g .
\end{aligned}
$$

Note that when $\Omega=1$, the two penalty rates go to infinity. Intuitively, when the government does not care about the contract costs (i.e., $\phi=0$ ) no limit exists on the competition between the government and the interest group. ${ }^{16}$

How effective is the government contract in removing the central banker's inflationary bias? Can this contract restore the money growth and inflation rates that prevail under credible commitment? Substituting $t^{N}$ and $\tau^{N}$ into the public's expectations about inflation and money growth produces

$$
m^{e}=\left(\frac{\psi \beta}{b \xi \alpha}\right) g \text {. }
$$

\footnotetext{
${ }^{15}$ Chortareas and Miller (2002) show that in the one-principal model, central banker contracts cannot eliminate the central banker's inflationary bias when the government cares about contract costs $(\Omega<1)$.

${ }^{16}$ As the marginal penalty rates rise, the fixed payments $\left(t_{0}\right.$ and $\left.\tau_{0}\right)$ must also increase to keep the net reward from the contracts positive. See further discussion on this issue below in section 5.
} 
Given that $\psi, \beta, \xi, \alpha$, and $b$ are positive, the public's expectations about the rate of money growth is positive. Therefore, the actual inflation is

$$
\pi=\left(\frac{\psi \beta}{b \xi \alpha}\right) g+v-\left(\frac{\alpha}{\alpha^{2}+\beta}\right) \varepsilon
$$

which exceeds the inflation rate under credible precommitment and under the Walsh (single-principal) contract. The resulting inflation rate is higher than, equal to, or lower than the discretionary inflation rate [i.e., $\left.\pi^{d}=(\alpha / \beta) z\right]$ as follows:

$$
\left(\frac{\psi \beta^{2}}{b \xi \alpha^{2}}\right) g=\left\{\begin{array}{l}
>z \\
=z \\
<z
\end{array}\right.
$$

Also note that from equation (11), we have that

$$
\left(\frac{1}{1-\Omega}\right)\left(\frac{\psi \beta^{2}}{b \xi \alpha^{2}}\right) g=\left\{\begin{array}{l}
>z \\
=z \Rightarrow \tau^{N}=\left\{\begin{array}{l}
>0 \\
<z
\end{array}=0 .\right. \\
<0
\end{array} .\right.
$$

Proposition 1: When a government-designed central banker inflation contract competes with an interest group's output contract, then the interest group's output contract dominates the government's inflation contract in affecting the central banker's incentives.

Proof: Assume that only the private interest group (with an expansionary bias) offers an incentive scheme to the central banker, while the government does not. Then the central banker's loss function (equation 4) includes only the private interest group contract. The central banker's and the public's reaction functions are given as follows:

$$
\begin{aligned}
& m=\left(\gamma-\frac{\alpha}{\left(\alpha^{2}+\beta\right)}\right) \varepsilon+\left(\frac{\alpha^{2}}{\alpha^{2}+\beta}\right) m^{e}+\left(\frac{\alpha^{2}}{\alpha^{2}+\beta}\right) z+\left(\frac{\xi}{2\left(\alpha^{2}+\beta\right)}\right) \tau \alpha, \text { and } \\
& E(m)=m^{e}=E(\pi)=\pi^{e}=\left(\frac{\alpha}{\beta}\right) z+\left(\frac{\xi}{2 \beta}\right) \tau \alpha .
\end{aligned}
$$

The interest group's optimal penalty rate is now given by 


$$
\tau^{N}=\left(\frac{2 \beta}{\xi \alpha}\right)\left[\left(\frac{\varphi \beta}{b \xi \alpha}\right) g-\left(\frac{\alpha}{\beta}\right) z\right]
$$

Therefore, the public's expectation about money growth and the actual inflation rate are given by

$$
\begin{aligned}
& m^{e}=\left(\frac{\psi \beta}{b \xi \alpha}\right) g, \text { and } \\
& \pi=\left(\frac{\psi \beta}{b \xi \alpha}\right) g+v-\left(\frac{\alpha}{\alpha^{2}+\beta}\right) \varepsilon .
\end{aligned}
$$

Equations (18) and (19) match the money growth expectation and inflation rate when both principals offer competing incentive schemes to the central banker (equations 13 and 14).

$Q E D$

Thus, in the presence of more than one potential principal, monetary policy delegation through contracts may be self-defeating. ${ }^{17}$ But why should the interest group offer a contract since, as easily verified, output remains at its natural level? Is there a problem? No, the result matches the typical outcome of timeinconsistency models using the Barro-Gordon framework. The interest group "represents" the fraction of society that wants the discretionary monetary policy regime. When society announces that monetary policy is delegated through contracts that are known to deliver equivalent-to-commitment results, the interest group attempts to restore the discretionary regime. In other words, that output may not exceed its natural level does not result from how we model common agency, but rather reflects a standard feature of the time-inconsistency literature in monetary policy. ${ }^{18}$ Of course, if the interest-group-offered contract is not public information, output exceeds its natural level by $(\psi \beta / b \xi) g$ (but we do not want to introduce such information asymmetries).

\footnotetext{
${ }^{17}$ Detailed welfare analysis results for this and following propositions are available from the authors. We do not provide them here because our main focus is to demonstrate the perils of delegation through contracts in the presence of more than one principal.

${ }^{18}$ Despite criticisms (e.g. McCallum 1995,1997), this result remains a standard feature of the time-inconsistency literature.
} 


\section{Central Banker Contracts and An Interest Group with an Inflation Objective}

Modeling the interest group to desire output in excess of the natural level seems more plausible than modeling the interest group to have preferences for higher inflation. Indeed, powerful interest groups with preferences for higher output or higher employment may include industry, trade unions, or national governments, when the central banker is the ECB (see, for example, Dixit 1998). One problem with such interest group contracts, however, is that if the reward of the central banker depends on observable policy outcomes, then the central banker is always punished. As long as the private sector incorporates the interest group contract, then the central banker's effort to increase output beyond trend is futile.

In this section, we model the interest group's objectives in terms of inflation. The interest group seeks higher inflation and offers an inflation based performance contract to the central banker. The central banker dislikes inflation more than the interest group. ${ }^{19}$ Indeed, it is more realistic to assume that the central banker is more inflation averse than the interest group that wants a more inflationary policy. Who will want to do so? Those who gain from higher inflation. Borrowers gain from unanticipated inflation that depreciates the value of the claims against them. A national government (if the central bank is the ECB) may want higher seignorage revenue.

The interest group's targeted inflation rate $\hat{\pi}$ can be equal to, lower than, or higher than $\pi^{d}$. Thus, the interest group's linear inflation contract takes the form $\left[\tau_{0}-\tau(\hat{\pi}-\pi)\right]$, where $\tau_{0}$ is a fixed payment and $\tau$ is the marginal penalty rate.

As before, the central banker and government (society) possess the same loss function. Thus, the central banker minimizes the loss function

$$
\Lambda^{C B}=\left[\left(y-y^{*}\right)^{2}+\beta \pi^{2}\right]-\xi\left[\tau_{0}-\tau(\hat{\pi}-\pi)+\left(t_{0}-t \pi\right)\right],
$$

given that the interest group and the government follow their optimal policies. Deriving the first-order conditions and solving for the central banker's reaction function gives:

${ }^{19}$ Blinder (1998) criticizes models where the central banker possesses a stronger inflation bias than society. 


$$
m=\left(\gamma-\frac{\alpha}{\left(\alpha^{2}+\beta\right)}\right) \varepsilon+\left(\frac{\alpha^{2}}{\alpha^{2}+\beta}\right) m^{e}+\left(\frac{\alpha^{2}}{\alpha^{2}+\beta}\right) z+\left(\frac{\xi}{2\left(\alpha^{2}+\beta\right)}\right)(\tau-t) .
$$

The private sector's expectation about inflation is given by:

$$
E(m)=m^{e}=E(\pi)=\pi^{e}=\left(\frac{\alpha}{\beta}\right) z+\left(\frac{\xi}{2 \beta}\right)(\tau-t) .
$$

The interest group minimizes its loss function of the form:

$$
\operatorname{Min}_{\tau} L^{I G}=\left[\left(y-y^{*}\right)^{2}+b(\hat{\pi}-\pi)^{2}\right]+\psi\left[\tau_{0}-\tau(\hat{\pi}-\pi)\right]
$$

subject to the private sector's expectation about money growth and inflation (equation 22) and the government's optimal marginal penalty rate. Using equations (1), (3), and (23), we derive the following optimal marginal penalty rate for the interest group:

$$
\tau^{N}=\Omega^{\prime}\left(\left(\frac{2 \beta}{\xi}\right)\left(\hat{\pi}-\left(\frac{\alpha}{\beta}\right) z\right)+t\right)
$$

where $\Omega^{\prime}=\left(\frac{(\xi b / \beta)+\psi}{(\xi b / \beta)+2 \psi}\right)<1$, provided that the interest group cares about contract costs. The marginal penalty rates of the government and the interest group are positively related. Higher $t$ means that the government penalizes more intensively deviations of actual inflation from the society's preferred inflation rate (which is zero). The interest group that possesses high inflation preferences must penalize more intensively deviations of actual inflation from its preferred rate of inflation $(\hat{\pi})$ to counteract the government incentive scheme. The interest group's inflation rate choice $(\hat{\pi})$ also positively affects $\tau$. The negative relationship between the marginal penalty rate and the central banker's inflationary bias $(z)$ emerges because the stronger the central banker's own incentive to inflate is, the less is the need for a strong incentive offered by the interest group

The government's problem consists of designing a dominant contract for the central banker, if one exists. Thus, the government chooses the marginal penalty rate that minimizes equation (9) subject to 
the public sector's expectations about inflation (equation 22). The optimal government marginal penalty rate that emerges is as follows:

$$
t^{N}=\Omega\left(\frac{2 \beta}{\xi}\left(\frac{\alpha}{\beta}\right) z+\tau\right),
$$

where $\Omega$ is defined above.

The government's optimal marginal penalty rate that incorporates the optimal marginal penalty rate of the interest group $(\tau)$ is given by

$$
t^{N}=\left(\frac{\Omega}{1-\Omega \Omega^{\prime}}\right)\left(\frac{2 \beta}{\xi}\right)\left[\left(1-\Omega^{\prime}\right)\left(\frac{\alpha}{\beta}\right) z+\Omega^{\prime} \hat{\pi}\right],
$$

while the interest group's optimal marginal penalty rate that incorporates the government's optimal marginal penalty rate is given by

$$
\tau^{N}=\left(\frac{\Omega^{\prime}}{1-\Omega \Omega^{\prime}}\right)\left(\frac{2 \beta}{\xi}\right)\left[\hat{\pi}-(1-\Omega)\left(\frac{\alpha}{\beta}\right) z\right] .
$$

In equilibrium, the government and the interest group pursue their optimal policies and the private sector (public) forms its expectations accordingly. Thus, using equations (26) and (27) and the private sector's expectations produces

$$
m^{e}=\pi^{e}=\left(\frac{1-\Omega}{1-\Omega \Omega^{\prime}}\right)\left[\left(1-\Omega^{\prime}\right)\left(\frac{\alpha}{\beta}\right) z+\Omega^{\prime} \hat{\pi}\right] .
$$

As $\Omega^{\prime}$ varies from $1 / 2$ to 1 , the term in brackets varies from $[(1 / 2)(\alpha / \beta) z+(1 / 2) \hat{\pi}]$ to $\hat{\pi}$.

Proposition 2a: When a government-designed central banker inflation contract competes with an interest group's inflation contract incorporating an inflationary bias, the government contract dominates the interest group's contract in affecting the central banker's incentives provided that the government does not care about the contract costs $(\Omega=1)$, but the interest group does $\left(\Omega^{\prime}<1\right)$. 
Proof: When the government does not care about the contract costs $(\Omega=1)$, but the interest group does $\left(\Omega^{\prime}<1\right)$, then equation (28) becomes $m^{e}=\pi^{e}=0$. But, this is precisely the outcome under the optimal Walsh contract. $Q E D$

Proposition 2b: When a government-designed central banker inflation contract competes with an interest group's inflation contract incorporating s an inflationary bias, the interest group contract dominates the government's contract in affecting the central banker's incentives provided that the government cares about the contract costs $(\Omega<1)$, but the interest group does not $\left(\Omega^{\prime}=1\right)$.

Proof: Consider equation (28) when the government cares about the contract costs $(\Omega<1)$, but the interest group does not $\left(\Omega^{\prime}=1\right)$. The private sector's expectations about the money growth rate and the inflation rate (equation 28) become

$$
m^{e}=\pi^{e}=\hat{\pi} .
$$

Assume now that only the private interest group with an inflationary bias offers a contract to the central banker. Then the loss function of the central banker (equation 20) includes only the private interest group contract. The central banker's, the interest group's, and the public's reaction functions are given as follows:

$$
\begin{aligned}
& m=\left(\gamma-\frac{\alpha}{\left(\alpha^{2}+\beta\right)}\right) \varepsilon+\left(\frac{\alpha^{2}}{\alpha^{2}+\beta}\right) m^{e}+\left(\frac{\alpha^{2}}{\alpha^{2}+\beta}\right) z+\left(\frac{\xi}{2\left(\alpha^{2}+\beta\right)}\right) \tau, \\
& E(m)=m^{e}=E(\pi)=\pi^{e}=\left(\frac{\alpha}{\beta}\right) z+\left(\frac{\xi}{2 \beta}\right) \tau, \text { and } \\
& \tau^{N}=\Omega^{\prime}\left(\frac{2}{\xi}\right)[\beta \hat{\pi}-\alpha z]
\end{aligned}
$$

Thus, the private sector's expectation for money growth that incorporate the reaction function of the interest group is given by

$$
E(m)=m^{e}=E(\pi)=\pi^{e}=\left(1-\Omega^{\prime}\right)(\alpha / \beta) z+\Omega^{\prime} \hat{\pi} .
$$


When the interest group does not care about the contract costs $\left(\psi=0\right.$ and thus $\left.\Omega^{\prime}=1\right)$ then equation (33) becomes

$$
m^{e}=\pi^{e}=\hat{\pi}
$$

But equation (34) matches equation (29). $Q E D$

Proposition 2c: When a government-designed central banker inflation contract competes with an interest group's inflation contract incorporating an inflationary bias and when both the government and the interest group care about the contract costs, then the expected inflation rate is positive but less than the expected inflation rate when the interest group contract fully dominates the government's contract in affecting the central banker's incentives provided that $\hat{\pi}>(1-\Omega)(\alpha / \beta) z$.

Proof: When the interest group contract dominates the government contract, the expected money growth rate and the expected inflation rate are given by equation (29). Setting $\Omega^{\prime}<1$ and $\Omega<1$ in equation (28) and subtracting from equation (29) produces $\left\{\left(\frac{1-\Omega^{\prime}}{1-\Omega \Omega^{\prime}}\right)[\hat{\pi}-(1-\Omega)(\alpha / \beta) z]\right\}$. Thus, when $\hat{\pi}>(1-\Omega)(\alpha / \beta) z$ the expected money growth rate and the inflation rate fall below those under full dominance of the interest group's contract. $Q E D$

The condition $\hat{\pi}>(1-\Omega)(\alpha / \beta) z$ is plausible. The term $(\alpha / \beta) z$ represents the central banker's own inflationary bias. The central banker's own inflationary bias falls short of the interest group's inflationary bias $(\hat{\pi})$ because otherwise no reason exists for the interest group to offer the contract to the central banker. In addition, the central banker's inflationary bias is multiplied by a fraction $(0<(1-\Omega)<1, \Omega<1)$.

\section{Discussion and Implications}

The existing literature on central banker contracts shows that an incentive scheme exists that counteracts the central banker's inflationary bias and induces the first-best outcomes. This optimal contract emerges from the difference between the central banker's reaction function under discretion and in the presence of 
the contract (Walsh 1995a). Once we introduce more than one principal, however, questions as to the efficacy and desirability of central banker contracts arise.

We consider the optimizing behavior of the central banker and two principals in a common agency model of central banker contracts. A disaffected interest group with an expansionary (output) bias or with an inflationary bias exists. When an interest group possesses an output bias, central banker inflation contracts do not deliver the optimal policy outcomes because the contract offered by the interest group dominates the contract offered by the government. When the interest group possesses an inflation bias, then the outcome depends on the willingness of the two principals to incur contract costs. In particular, when the government does not care about contract costs, but the interest group does, the expected inflation rate is zero. The private sector recognizes that the government inflation contract dominates the interest group contract and behaves as it does when only a government optimal (Walsh) contract exists. When the government cares about contract costs, but the interest group does not, the interest group contract dominates. Finally, when both principals care about contract costs, an interior solution emerges with a positive inflation rate, but one less than that preferred by the interest group.

Under Walsh's implicit assumption that the government places no weight on contract costs, the optimal outcome prevails when an interest group with an inflation bias attempts to influence the central banker's decisions. This assumption, however, may be too strong. The optimal penalty rates in the contracts offered by the government and interest group depend on each other (see equations 8, 10, 24, and 25). For the contracting approach to make sense, however, the net transfer to the central banker must always be positive. The fixed amount in the government's and interest group's reward schemes $\left(\mathrm{t}_{0}\right.$ and $\left.\tau_{0}\right)$ is irrelevant when deriving the optimal contract in the single principal (Walsh) model. When a second principal enters the model and offers a competing contract, then the fixed component in the central banker contract becomes relevant, since the principals cannot face a limit to the fixed payment $\left(\mathrm{t}_{0}\right.$ and $\left.\tau_{0}\right)$ that they can offer. We assume, however, that the principals do not face such constraints. 
When the interest group possesses an expansionary bias and the government does not care about the contract costs, then an infinite competition between the government and the interest group contract develops (see equations 11 and 12). As the marginal penalty rates increase, responding to each other, the fixed payments must rise to keep the net reward to the central banker positive. Assume that the realized inflation rate exceeds zero, but is low enough so that the central banker receives a positive net reward even after being penalized for the positive inflation outcome. Given the fixed amount in the incentive scheme (from which the penalty is subtracted), if a second principal now offers a dominant contract to the central banker, then the power of this contract is lower than the power of the contract in the world with the single principal. If the government wants the dominant contract to retain the power equivalent to that of the single-principal contract, then the fixed payment must rise. This condition holds regardless of whether the central banker achieves zero or positive inflation rates, because the contract is designed before the policy is implemented and outcomes occur.

The last result has interesting implications. First, the expected social costs of the dominant contract become higher. More interestingly, the magnitude of the optimal penalty rate in the dominant contract depends on the optimal penalty rate in the interest group contract. This last penalty rate depends, in turn, on the expansionary bias of the interest group and the degree of central banker's selfishness. Typically, a government does not face a resource constraint that prevents it from financing the central banker contract. Institutional constraints probably exist, however, requiring that the central banker's reward scheme does not violate some upper bound, since extremely high reward payments may be politically unacceptable. On the other hand, the interest group probably does not face such limits. Thus, the dominant contract is not feasible, when an interest group offers a contract to the central banker. This occurs because an effective dominant contract requires an excessively high fixed reward for the central banker.

Our results largely depend on the nature of the bias that the interest-group-offered contract possesses, since the government contract attempts to eliminate the central banker's inflationary bias. 
Under these conditions, when the central banker's inflationary bias competes with the interest group's expansionary bias, the contract based on inflation performance cannot deliver the commitment-equivalent results. The interest group's output contract dominates.

Finally, both our model and results differ from Dixit and Jensen's (2000) in several respects. First, we address a different and more general question. In particular, Dixit and Jensen (2000) ask the question "what are the policy outcomes under multi-principal contracts in a monetary union"; we ask the question "do optimal central banker contracts exist under common agency?" Second, Dixit and Jensen (2000) assume that the principals agree on the direction of desirable policy targets; we model principals as having explicitly conflicting objective. Third, their results indicate that the Nash policy outcomes can be Pareto efficient while our results show that introducing common agency considerations implies higher inflation through its effect on expectations. Fourth, we focus explicitly on the relative concern about the costs/rewards implied by the incentive scheme and welfare for both the principal and the central banker. Finally, in addition to inflation contracts we also consider output contracts.

\section{Conclusion}

In this paper, we extend the basic principal-agent model in central banking to allow for the presence of a second potential principal (a disaffected interest group). Although the central banker's selfishness is the sine-qua-non of the contracting approach, it may open Pandora's box since a selfish central banker may respond to contracts offered by a principal other than the government. We develop a simple common agency model with two principals, and define and characterize the resulting equilibria. We show that when an interest group (second principal) prefers higher money growth than government (society), government can still design a contract that delivers policy outcomes equivalent to the credible precommitment outcomes only under certain conditions. In particular, we show that a dominant contract written in terms of the central banker's inflation performance does not exist when an interest group with an expansionary bias lobbies the central banker. When the interest group possesses an inflationary bias, however, the outcome varies depending on its and the government's willingness to incur contract costs. If 
government (society) can offer the optimal dominant contract, then the expected social loss equals that under the single-principal inflation contract (a la Walsh). This result emerges because a credible dominant contract eliminates the incentives of the interest group to offer its own contract. In other words, the optimal contract for the common agency model in central banking is efficient (this result is consistent with Dixit et al. 1997, and Bernheim and Whinston 1986a). This contract, however, differs from the single-principal (government) contract. When the possibility of more than one principal occurs, policy outcomes different from the optimal (credible precommitment) arise. In addition, designing a dominant contract proves untenable. In sum, our results cast doubt on the efficacy and desirability of central bank contracts. While the principal-agent approach to central banking provides the natural framework for considering delegation, the mapping of theoretical results to practical policy design remains a challenge. Our discussion raises questions of the credibility of the optimal contracts in the eyes of the public, the mutual exclusiveness of them, the appropriate variable to measure the central banker's performance (i.e., inflation versus output) in the government's contract, and the interaction of the delegation form with transparency in policymaking. Those questions constitute the subject of our further research. 


\section{References}

Ahmed, H., and S. M. Miller (1998) "Monetary and Exchange Rate Policies in Multisectoral Economies." Journal of Economics and Business, Vol. 49, No. 4, 321-334.

Alesina, A., and H. Rosenthal (1995) Partisan Politics, Divided Government and the Economy. Cambridge University Press.

Barro, R. and D. Gordon (1983) "Rules, Discretion, and Reputation in a Model of Monetary Policy." Journal of Monetary Economics, Vol. 12, No. 1, 101-121.

Bernheim, B. D., and M. D. Winston (1986a) “Common Agency.” Econometrica, Vol.54, No. 4, 923-942.

Bernheim, B. D., and M. D. Winston (1986b) "Menu Auctions, Resource Allocation, and Economic Influence.” The Quarterly Journal of Economics, Vol. 101, Issue 1, 1-31.

Blinder, Alan S. (1998) Central Banking in Theory and Practice. The MIT Press.

Brunner, K. (1985) "Monetary Policy and Monetary Order." in Monetary Policy and Monetary Regimes, Graduate School of Management, University of Rochester.

Canzoneri, M. (1985) "Monetary Policy Games and the Role of Private Information." American Economic Review, Vol. 75, No. 5, 1056-1070.

Canzoneri, M., C. Nolan, and A. Yates (1997) "Mechanisms for Achieving Monetary Stability: Inflation Targeting versus the ERM." Journal of Money Credit and Banking, Vol. 29, No. 1, 46-60.

Chortareas, G. E., and S. M. Miller (2002) "Monetary Policy Delegation, Contract Costs, and Contract Targets," (forthcoming), Bulletin of Economic Research.

Chortareas, G. E., D. Stasavage, and G. Strerne, (2002), "Does It Pay to Be Transparent? International Evidence from Central Bank Forecasts," (forthcoming), Federal Reserve Bank of St. Louis Review.

Dewatripont, M., F. Giavazzi, J. von Hagen, I. Harden, T. Persson,G. Roland, H. Rosenthal, A. Sapir A., and G. Tabellini (1995) Flexible Integration: Towards a More Effective and Democratic Europe. Centre for Economic Policy Research (CEPR).

Dixit, A. (1996a) "Special-Interest Lobbying and Endogenous Commodity Taxation." Eastern Economic Journal, Vol. 22, No.4, 375-387.

Dixit, A. K. (1996b) The Making of Economic Policy: A Transaction-Cost Politics Perspective. The MIT Press.

Dixit, A. K., and Jensen H. (2000) "Equilibrium Contracts for the Central Bank of a Monetary Union," mimeo.

Dixit, A., E. Helpman, and G. M. Grossman (1997) "Common Agency and Coordination: General Theory and Application to Government Policy Making." Journal of Political Economy, Vol. 105, No. 4, 752-769. 
Eichengreen, B. (1996) “A More Perfect Union? The Logic of Economic Integration." Essays in International Finance, No. 198, Princeton University.

Fisher, A. (1995) "New Zealand's Experience with Inflation Targets." in L. Leiderman and L. E. O. Svensson (eds.), Inflation Targets, London, Centre for Economic Policy Research; distributed in North America by the Brookings Institution, Washington, D.C., 32-52.

Fratianni, M., J. Von Hagen, and C. Waller (1997) "Central Banking as a Political Principal-Agent Problem.” Economic Inquiry, Vol. 35, 378-393.

Garfinkel, M. R., and S. Oh (1993) "Strategic Discipline in Monetary Policy with Private Information." American Economic Review, Vol. 83, No. 1, 99-117.

Gordon, R. M. (1975) "The Demand and Supply of Inflation." Journal of Law and Economics, Vol. 18, No. 3, 807-836.

Grossman, G., and E. Helpman (1994a) "Protection for Sale.” American Economic Review, Vol. 84, 833-50.

Grossman, G., and E. Helpman (1994b) "Electoral Competition and Special Interest Politics." Review of Economic Studies, Vol. 63, 265-286.

Grossman, G., and E. Helpman (1995) "Trade Wars and Trade Talks." Journal of Political Economy, Vol. 103, No. 4, 675-708.

Henning, R. C. (1994) Currencies and Politics in the United States, Germany and Japan. Institute for International Economics.

Jensen, H. (1997) “Credibility of Optimal Monetary Delegation.” American Economic Review, Vol. 87, No. $5,911-920$.

Laffont, J. J., and J. Tirole (1993) A Theory of Incentives in Procurement and Regulation. The MIT Press.

Leiderman, L. and L. E. O. Svensson, (eds.) (1995) Inflation Targets, London, Centre for Economic Policy Research; distributed in North America by the Brookings Institution, Washington, D.C.

Levy, P. I. (1999) "Lobbying and International Cooperation in Tariff Setting," Journal of International Economics, Vol. 47, No. 2, April, 345-370.

Mayer, T. (1990) (ed.) The Political Economy of American Monetary Policy. Cambridge University Press.

McCallum, B. T. (1995) “Two Fallacies Concerning Central Bank Independence.” American Economic Review Papers and Proceedings, Vol. 85, 207-211.

McCallum, B. T. (1997) "Crucial Issues Concerning Central Bank Independence." Journal of Monetary Economics, Vol. 39, No. 1, June, 99-112.

Persson, T. (1998) "Economic Policy and Special Interest Politics." The Economic Journal, March, 310327. 
Persson, T., and G. Tabellini (1993) "Designing Institutions for Monetary Stability." Garnegie-Rochester series on Public Policy, Vol. 39, 33-84.

Posen, A. (1993) "Why Central Bank Independence Does Not Cause Low Inflation: There Is No Institutional Fix For Politics." in Richard O'Brien (editor) Finance and the International Economy: 7. Oxford University Press for The Amex Bank Review, 41-54.

Posen, A. (1995) "Declarations Are Not Enough: Financial Sector Sources of Central Bank Independence." in NBER Macroeconomics Annual, The MIT Press, 252-274.

Rogoff, K. (1985) “The Optimal degree of Commitment to an Intermediate Monetary Target." Quarterly Journal of Economics, Vol. 100 (November), 1169-89.

Spiller, P. T. (1990) "Politicians, Interest Groups, and Regulators: A Multiple Principals Agency Theory of Regulation, or 'Let Them Be Bribed."' Journal of Law and Economics, Vol. 33, April, 65-101.

Svensson, L. E. O. (1997) "Optimal Inflation Targets, "Conservative" Central Banks, and Linear Inflation Contracts" American Economic Review, Vol. 87, 98-114.

Waller, C. J. (1992) "The Choice of a Conservative Central Banker in a Multisectoral Economy" American Economic Review, Vol. 82, No. 4, 1006-1012.

Waller, C. J. (1995) "Performance Contracts for Central Bankers," Federal Reserve Bank of St. Louis Economic Review, September/October, 3-14.

Walsh, C. E. (1995a) “Optimal Contracts for Central Bankers.” American Economic Review, Vol. 85, No. 1, 150-167.

Walsh, C. E. (1995b) "Is New Zealand's Reserve Bank Act of 1989 an Optimal Central Bank Contract?" Journal of Money, Credit and Banking, Vol. 27, No. 4, 1179-1191. 